\title{
EDUCACIÓN EN VALORES EN ESTUDIANTES DE EDUCACIÓN SECUNDARIA OBLIGATORIA
}

\author{
Gracia Nacarí Lara Guardia y José Miguel García Ramírez. Universidad de Granada
}

Fecha de recepción: 10 de julio de 2014

Fecha de revisión: 20 de julio de 2014

Fecha de aceptación: 30 de julio de 2014

\section{RESUMEN}

El objetivo de este estudio es analizar el tipo de necesidades de Educación en Valores que existen en una muestra de 147 alumnos y alumnas de Educación Secundaria Obligatoria de un centro público de la provincia de Granada. Para ello se ha realizado un análisis de la propia documentación del centro, se ha llevado a cabo una observación directa durante un mes y medio del alumnado del centro, y se han analizado las respuestas otorgadas por los estudiantes a un cuestionario de respuestas abiertas, de elaboración propia. Los resultados nos indican como las necesidades en valores que existen en este centro son variadas y como, de forma relativamente general, la mayoría los estudiantes presenta un porcentaje de conocimiento bajo acerca de los valores, inferior al 50\%, exceptuando el caso de los dos grupos bilingües mayores de la E.S.O. que, significativamente han obtenido una puntuación superior al $50 \%$.

PALABRAS CLAVE: Educación Secundaria, moral, valores, motivación, orientación.

El considerar que las cosas son buenas y el sentir que éstas son dignas de ser apreciadas, prestándoles esa atención que merecen, es darles ese gran valor humano que toda persona posee. Todas las cosas encierran un valor, que cada individuo ira descubriendo de forma muy diferente, en función de su inteligencia, experiencias y voluntad. Por ello, no cabe duda que la enseñanza y la transmisión de los valores potencia la adquisición y la puesta en práctica de los mismos, a lo largo de la vida de todos los sujetos.

Los diferentes valores humanos que son adquiridos por las personas están influenciados por muchos factores como, por ejemplo, las experiencias dentro del colegio, en la familia, en la calle, en la televisión, etc., pero son los propios sujetos los que los hacen suyos, formándose a sí mismos como personas y creando su propia personalidad e identidad. De esta forma, se debe de tener en cuenta que todos los niños y niñas, jóvenes y/o adultos irán apreciando el gran conjunto de valores, en la medida en que sean educados en los mismos y adquieran significado para ellos.

El educar en un clima o ambiente de buenos valores, es importante en tanto que ayuda a los individuos a guiar su vida y conformar su propia identidad como personas. Es por ello, que los valores ayudan a crecer y madurar tanto personal como socialmente, y permiten el desarrollo de unos comportamientos propios de una sociedad democrática, capaz de garantizar la libertad y humanidad para todos. Así la enseñanza de valores es considerada, hoy en día, una herramienta valiosa, capaz de 
prevenir y solucionar los conflictos interpersonales, violencia, discriminación, faltas de respeto, presencia de acciones y pensamientos racistas y xenófobos, etc. En definitiva, un recurso poderoso y un marco de referencia sustancial, para garantizar la existencia de unas sociedades democráticas, pacíficas y sociales, capaces de convivir en paz y armonía.

Debido a los enormes beneficios que generan los valores en la vida de todos y cada uno de los individuos, los profesionales que nos dedicamos a la educación, con los años, nos hemos visto en la responsabilidad de cambiar nuestro papel de simples transmisores de conocimientos y aprendizajes, al de grandes agentes humanos de formación de personas, capaces de enseñarles a actuar con conciencia y coherencia entre lo que piensan, dicen y hacen, de acuerdo a sus metas e ideales. Conseguir un clima de convivencia más humano, en el que todos los niños/as puedan convivir juntos, en el que se presencie la existencia de ayuda y solidaridad, donde haya respeto y donde se resuelvan pacíficamente los conflictos debe ser el objetivo de cualquier centro. No se trata de imponer valores, sino de ofrecer caminos y alternativas para que todos los estudiantes puedan emplearlos en sus vidas, según sus preferencias y su propio nivel de identificación con los mismos.

El educar para conseguir en el futuro este tipo de sociedades democráticas requiere, sin duda, perseguir e incorporar dentro de la educación reglada, una serie de objetivos, contenidos, actividades, etc., de acuerdo con esta meta, para promover este tipo de aprendizaje entre todos los estudiantes. Es por ello que se ha considerado pertinente la elaboración de esta investigación con objeto de proponer una serie de orientaciones, de cara a la mejora de la educación moral que se trabaja y transmite desde los centros educativos.

En la actualidad la educación basada en valores tiene una elevada importancia dentro de los centros educativos, ya que diversos estudios han comprobado como la disposición de una base firme en valores humanos, personales y/o sociales, fuertemente arraigada en las personas, actúa como un incentivo interno o elemento estimulador de la propia motivación intrínseca, que mueve e impulsa a la realización de una serie de conductas determinadas. Este es el motivo, que junto al deseo de crear una sociedad democrática y la necesidad de valores encontrada dentro de un centro, nos ha llevado a plantear una serie de orientaciones para la mejora de la Educación en Valores, transmitida desde los centros educativos, que presta especial atención al conjunto de valores mínimos que se recogen dentro del ámbito legislativo, y que constituye la propia base de la vida en común, en general, como la libertad personal, la igualdad, la justicia, la solidaridad, el respeto, la tolerancia, la responsabilidad y la ciudadanía democrática, entre otros. Estos valores tienen en común la particularidad de que se trabajan dentro de los centros educativos, desde dos propuestas diferentes, estrechamente relacionadas, de forma directa por medio del Plan de Acción Tutorial y Plan de Convivencia, e indirecta a través de los temas transversales. Además, son valores que forman parte del conjunto de las competencias éticas que se deben tratar de conseguir desde los centros educativos, por lo que se considera necesario planificar desde ellos una serie de competencias específicas que formen parte de la formación del alumnado, con el fin de que den sentido a su vida y a su modo de ver y hacer las cosas. (Casares, Carmona y Martínez, 2010)

\section{La conceptualización de los valores y su relevancia en los centros educativos}

Actualmente son muchos los estudios y las investigaciones que según Rodríguez (2012) hablan del concepto de valor, por lo que las definiciones que se han realizado 
acerca del mismo, con el paso de los años, han sido diversas. Barreto (2012) afirma que no es fácil conceptualizar este término de un modo inequívoco, ya que existen múltiples definiciones del mismo que hacen muy difícil su determinación, en una sola concreta.

El concepto de valor es el referente al grado de utilidad o aptitud de las cosas para satisfacer las necesidades o proporcionar bienestar o deleite. Pero una visión más amplia y completa de este concepto es la que plantea Mora (1995):

"Los valores están relacionados con las grandes convicciones humanas de lo que es bueno, de lo que es mejor y de lo que es óptimo; ellos tienen la facultad en sí mismos de proporcionar alegría, satisfacción y felicidad a todos quienes los poseen, aún cuando algunas veces sean dolorosas; por tanto son fundamentales en la búsqueda de la realización humana." (p. 113)

Lobato y Morilla (2007), por su parte, afirman que los valores son las cualidades que presentan las personas apreciadas por el hecho de favorecer sus propias necesidades humanas, naturales y culturales, el desarrollo de sus dimensiones como persona (la cognitiva, la social, la emocional, etc.), la construcción de su adecuada convivencia social, y la consecución de un mundo más justo y democrático. Asimismo estos valores son definidos por Barreto (2012) como el conjunto de cualidades que hacen interesante y apreciable a una persona u objeto. Para ello, se ayuda de la existencia de tres grandes criterios distintos que tratan de explicar el término de valor, uno de tipo ontológico, otro epistemológico y otro praxiológico-valorativo. El primero, defiende que los valores forman parte de la vida de todas las personas, de manera que dan significado a las actuaciones y producciones que éstas realizan. El segundo, considera que los valores pueden ser estudiados desde la conducta y comportamiento que tienen las personas dentro del mundo en el que viven. $Y$ el tercero, afirma que los valores deben ser explicados por medio de la influencia positiva que éstos pueden llegar a tener en el resto de personas, así como en la consecución de una mejor interacción entre todos los individuos. Martin y Puig (2007) defienden, por tanto, que a través de estos tres criterios podemos comprender como los valores dan sentido a la vida y a la forma de actuar o comportarse las personas.

Lobato y Morilla (2007) destacan una serie de características importantes acerca de los valores como son, por ejemplo, su carácter individual y colectivo, su bipolaridad y la jerarquía existente en torno a los mismos; por tanto los valores pueden ser interiorizados y compartidos, pueden hacerse latentes de manera positiva y/o negativa, y cada persona puede tener una escala o graduación de valores determinada, según sus propias preferencias. En relación a esta última característica se debe destacar la exhaustividad y precisión con que las personas deben definir su jerarquía de valores para desempeñar un comportamiento más personal, orientado y coherente, capaz de permitirles tomar una serie de diferentes decisiones en la vida, de manera autónoma y consciente (Martín y Puig, 2007).

Barreto (2012) añade a las tres características anteriores de los valores la propia de dependencia, porque considera que los mismos se encuentran adscritos a ciertos objetos en los que adquieren significado; historicidad, ya que cree que tienen carácter propiamente histórico y proceden de una serie de ideales que las personas tratan de hacer suyos e incorporar a su manera de proceder en la vida; durabilidad, por haberse mantenido con los años; flexibilidad, como consecuencia de que cada persona puede vivirlos de una forma diferente; carácter inagotable, debido a que no se agotan nunca y su uso y empleo puede ser cada vez mayor; funcionalidad-aplicabilidad, ya que pueden llevarse a la práctica; trascendencia, como consecuencia de que aportan calidad humana integral; satisfacción, porque constituyen experiencias emocionales que dan un sentido a la existencia humana; y estructuralidad, puesto que todos los 
individuos los incorporan como parte de una estructura en la que primero son observados, luego aprendidos e interiorizados y después realizados y puestos en práctica.

Los valores se pueden clasificar de muchas formas distintas, en función de los criterios que sean utilizados. Lobato y Morilla (2007) afirman que la mejor forma de clasificar y llevar a la práctica el desarrollo de una buena educación en valores en los individuos, es la que se centra en atender sus dimensiones como persona. Así, distinguen la existencia de unos valores de tipo cognitivo como la verdad, claridad o conocimiento; emocionales como la alegría, satisfacción o amistad; morales o éticos como la justicia, solidaridad o igualdad; estéticos como la belleza o deleite estético; corporales como la fortaleza, salud o higiene; sensoriales y sensuales como el placer o agrado; desiderativos como la deseabilidad; técnico-productivos como la eficiencia, utilidad o eficacia; socio-afectivos como la comprensión, empatía o aprecio; y sociopolíticos como la paz o democracia. Una característica peculiar de estos valores, es que no todos tienen la misma importancia dentro de los centros educativos, ya que unos son considerados más precisos y necesarios que otros.

A lo largo de los años han sido muchos los estudios que se han realizado acerca de los valores, y que han tratado de poner de manifiesto los más característicos e importantes para toda la sociedad, en general. Casado y Sánchez (1999) realizaron un estudio con el fin de descubrir cuáles eran las preferencias valorativas de los individuos en los contextos de enseñanza, a través de la utilización del test de valores de Casares (1995). Gracias a esta investigación comprobaron cómo los valores más importantes para el alumnado eran los de tipo afectivo, ecológico, ético, individual, corporal y social (encontrándose estos dos últimos a un mismo nivel), lo que sirvió para detectar la gran importancia otorgada a los valores éticos y sociales dentro de los contextos educativos.

Según Álvarez y Gutiérrez (2012) las investigaciones más actuales de los valores se encuentran sujetas en un modelo de construcción autónomo y racional, por parte de los propios individuos. De forma que, son éstos los que haciendo un uso libre e independiente de su razón, su diálogo e ilusión, elaboran una serie de criterios clave que determinan su conducta dentro de una sociedad democrática, abierta y plural donde existen unos espacios para la reflexión, intercambio de ideas y opiniones, y para la discusión y el análisis de las cosas que nos rodean, entre otras cuestiones.

Escámez (1998) afirma que la personalidad moral de los individuos se va construyendo a partir de las acciones voluntarias que éstos tienen dentro de su vida en sociedad, de forma que estos valores se tienen que aprender, practicar e interiorizar por los mismos. La finalidad de la educación moral es, consecuentemente, aquella conducta moral que puede llegar a aprenderse e interiorizarse conformando y consolidando los propios valores de la persona (Escámez, 2003). Así, Casares (2008) considera que la captación de los propios valores morales tiene su origen en la experiencia, por lo que ésta depende, en gran medida, de todas aquellas condiciones de tipo biológico, afectivo y situacional que las personas vivenciamos durante nuestra vida. Los valores que son adquiridos por medio de la socialización o aprendizaje personal, adquieren importancia en torno a dos grandes sentidos. En primer lugar, motivan las acciones que realizan las personas dándoles una dirección, sentido e intensidad emocional; y en segundo lugar, actúan como unos criterios indispensables para juzgar y justificar la propia acción (Casares, Carmona y Martínez, 2010).

Según Lobato y Morilla (2007) la rama de la filosofía que estudia y explica la propia naturaleza de los valores y su influencia en las personas es la axiología. De esta 
forma, Touriñán (2008a) defiende que la educación en valores es el proceso de maduración y aprendizaje por el cual las personas se desarrollan a lo largo de su vida para construir su experiencia axiológica, es decir, el conjunto de valores que lo conforman y lo identifican como persona. Por ello este autor propone que "la finalidad principal de la educación en valores es la de aprender a construir y utilizar la propia experiencia axiológica para poder desarrollar el propio proyecto de vida".

Atendiendo al proceso de educación en valores que se trabaja en los colegios e institutos se debe destacar a autores como Casado y Sánchez (1999), quienes consideran que este proceso educativo no se justifica tan sólo por la simple transmisión de unos conocimientos, destrezas y/o normas entre el alumnado, sino también por su participación en el incremento de su autonomía moral. Esto se debe, fundamentalmente, a que favorece el incremento de su criterio para llegar a comprender el mundo en el que viven. Lobato y Morilla (2007) definen así, que "la importancia de la educación radica principalmente en los valores que ésta cultiva, ya que una educación sin valores no es educación..., educar es siempre perfeccionar, optimizar, completar, mejorar..., en definitiva, hacer más valioso y completo al ser humano". Por su parte Martín y Puig (2007) defienden que la finalidad o intención principal de la educación en valores es la de ayudar a los estudiantes a adoptar una forma de vida en la que ellos mismos quieran vivir. La educación en valores no es, por tanto, sólo una meta que deba ser trabajada por las familias del alumnado, sino que ésta ha de ser también propiciada por la escuela, los medios de comunicación y/o la convivencia con el propio grupo de iguales entre otros muchos caminos. Tuts y Martínez (2006) afirman que educar en valores "no es sólo educar desde la escuela, sino desde todos los ámbitos de formación, es formar a personas para su integración en la sociedad y su participación ciudadana solidaria y responsable".

Casares (2008) considera que la educación en valores debe de contemplar unos aspectos intelectuales, afectivos, volitivos y de conducta, ya que entiende que para que el alumnado adquiera una serie de valores se considera necesario que tenga, al menos, un breve conocimiento de los mismos; una preferencia por aquellos con mayor nivel de significación e interés afectivo-emocional; y una voluntad de querer introducirlos en su forma de actuar y proceder en la vida. Estos son los aspectos que, según Touriñán (2008a), constituyen la propia educación integral de la persona y contribuyen en su propio desarrollo profesional, personal, familiar y social, entre otras cuestiones. Este mismo autor (2008b) defiende que la educación en valores es importante en cuanto a que permite que las personas puedan tener un conocimiento de los mismos, realizar una estimación personal (preferencia) sobre ellos y adquirirlos a lo largo de la vida y, porque considera que la relación acontecimiento-acción es todo un reto en educación en valores, debido a que permite comprender a las personas la importancia que tiene el realizar los valores una vez que han sido elegidos.

Escámez, García, Pérez y Llopis (2007) defienden que los distintos docentes tienen una responsabilidad muy elevada y especial en el desarrollo de los valores que se desarrollan dentro de los centros educativos, ya que, en primer lugar, deben ser ellos mismos y, en segundo lugar, deben de estimular, guiar y propiciar que todo el alumnado lo sea también. Para poder llegar a conseguir esto, es necesario que el profesorado que trabaja en los diferentes colegios e institutos adquiera una serie de competencias en relación a estas cinco cuestiones: una formación inicial, continua y permanente para la construcción y consolidación de unos esquemas de decisión que permitan atender las necesidades reales de la propia práctica profesional; el desarrollo de unas apropiadas prácticas educativas; la transmisión de un conocimiento capaz de llegar al alumnado; la combinación simultánea y equilibrada de una formación teórica y práctica, capaz de atender las necesidades de la propia realidad educativa; y el impulso de una serie de grandes propuestas que permitan reformular la cultura moral 
de la escuela, la integración de tareas y actividades de educación moral, la formación para el ejercicio de la tutoría y la consolidación de un estilo docente más justo y democrático (Martínez, Puig y Trilla, 2003).

El clima que crea el profesorado en sus aulas influye, en gran medida, en aquellos valores que el alumnado adquiere dentro de este contexto. Esto se debe, esencialmente, a que la creación de un espacio o ambiente propicio y seguro, en el que todo el alumnado tiene completa libertad de expresión y elección, favorece el aprendizaje de los valores en los sujetos y el desenvolvimiento personal de escucha empática (Escámez, García, Pérez y Llopis, 2007; Garcia-Ramirez, 2012).

\section{La motivación que se desarrolla de forma intrínseca en el aula}

El concepto de motivación es delimitado como la acción o efecto de motivar; en segundo lugar, es concretado con el término motivo (causa que mueve a los individuos hacia la consecución de un fin determinado); y en tercer lugar, es definido como el ensayo mental preparatorio de una acción concreta para animar y/o animarse a ejecutarla, con interés y diligencia. Según Gálvez (2006), son muchos los autores que señalan principalmente la existencia de dos grandes tipos de motivación: la intrínseca y la extrínseca. La primera, se refiere a la motivación que nace del individuo, quien quiere hacer algo por sí mismo y tiene voluntad de actuar; y la segunda, a la motivación que no nace de éste, sino de personas externas al mismo y de las circunstancias que lo rodean.

El desarrollo de la motivación intrínseca en el aula es considerado un aspecto esencial e importante, ya que contribuye a que el alumnado adopte actitudes positivas hacia su proceso de aprendizaje y muestre interés hacia las diversas disciplinas que estudia. Cuando este tipo de motivación intrínseca se desarrolla de manera adecuada a la capacidad del alumnado y discurre sin ningún tipo de dificultad, no se considera preciso otorgar premio o castigo alguno tras la misma, debido a que los/as estudiantes experimentan la motivación como satisfactoria y es su funcionamiento, en sí mismo, el que les proporciona placer (Aebli, 2002).

Manassero (1998) afirma que la motivación intrínseca es la que más nos acerca a la consecución de la motivación de logro. Siendo el impulso que mueve a los individuos a la superación de todas aquellas situaciones que exigen rendimiento, la preocupación por hacer bien las cosas, el logro de unos objetivos concretos, y el alcance de unos resultados óptimos. Dentro del ámbito educativo, esta motivación de logro ejerce un papel importante, debido a que no sólo influye en la acción académica del alumnado, sino también en su propio rendimiento (Álvarez y Bisquerra, 2012). Así, la motivación y el esfuerzo por aprender depende de las metas y los intereses para formarse, de las expectativas para conseguir todas las consecuencias buscadas, de los conocimientos y las estrategias de autorregulación del aprendizaje y de las consecuencias negativas de muy distinto tipo, que pueden seguirse (Alonso, 2005).

Los problemas relacionados con la falta de motivación son muy frecuentes, hoy día, en los centros educativos de Educación Secundaria Obligatoria. Esto se debe, según gran parte del alumnado, a que los contenidos de las diferentes materias que estudian suelen ser densos y poco atractivos, lo que hace que incremente su desinterés y desmotivación por las tareas y actividades que realizan dentro del aula. A este factor se unen otros muchos como la propia metodología y/o relaciones personales establecidas con el profesorado, la atención y ayuda prestada desde casa, o las características individuales presentes en cada estudiante. Eccles y Wigfield (2002) 
defienden que el alumnado afronta el trabajo que realiza en el aula y la escuela desde una triple orientación motivacional:

- la orientación hacia el aprendizaje, por la que buscan incrementar sus capacidades y su propio saber, poner en práctica sus competencias, ayudar a los otros, sentir apoyo del profesorado, etc.

- la orientación hacia el resultado, por la que buscan el propio reconocimiento social, la consecución de metas externas al aprendizaje, etc.

- la orientación hacia la evitación, por la que actúan por miedo a fracasar o sacar malas notas, por la que perciben las tareas y actividades escolares como inútiles, por la que carecen de estrategias y de disposiciones para hacer frente a la presión y el propio ritmo del trabajo de clase, etc.

No todo el alumnado trata de conseguir las mismas metas de aprendizaje dentro de la escuela, ya que unos trabajan y desarrollan estrategias para aprender, otros lo hacen por ser los primeros de la clase y destacar sobre el resto de compañeros/as, otros para mejorar el propio rendimiento, o evitar el castigo o el fracaso, y otros no trabajan, ni se esfuerzan, debido a que como defiende López (2005) las estrategias de aprendizaje que utilizan no son efectivas $y$, por tanto, las tareas escolares se conciben como irrelevantes. El grado de interés personal hacia un determinado contenido concreto, afecta de esta forma, a la cualidad y profundidad del esfuerzo y aprendizaje desarrollado (Hidi y Harackiewick, 2000).

Las motivaciones que mueven al alumnado a aprender y actuar dentro del aula, son tan variadas como diversas. Cid (2008) destaca, por su relevancia, diferentes tipos de motivación: la motivación como herramienta que permite que se comprenda la importancia que tiene el hecho de aprender a la hora de conseguir los objetivos propuestos; la motivación desarrollada ante una metodología concreta que implica que se interesen más por aquel aprendizaje que incluye una didáctica atractiva y participativa; la motivación como medio para generar una buena relación entre docentes y estudiantes; la motivación para lograr el éxito que conlleva a la consecución de todo lo propuesto, lo que supone además un refuerzo psicológico y motivacional; la motivación lograda del aprendizaje de la adquisición de conocimientos, del deseo de conseguir una carrera profesional, una profesión, etc.; y la motivación por desafío, creada a partir de la habilidad que tenga el profesorado para generar nuevos retos en el alumnado.

Alonso (1999) defiende que para motivar académicamente a todos los estudiantes, es necesario desarrollar una serie de actuaciones encaminadas a despertar la curiosidad, mostrar la relevancia de todo el contenido que se trabaja, facilitar el mantenimiento del interés durante la realización de la tarea, prestar atención a las interacciones que se realizan con los alumnos/as, desarrollar un trabajo cooperativo, facilitar una actuación autónoma, diseñar unas actividades que permitan pensar, y mostrar una atención a las dimensiones de la evaluación que afectan a la propia motivación. Para conseguir todos estos aspectos se requiere del desarrollo de adecuadas estrategias metodológicas dentro del aula, de la presencia de una apropiada actuación docente, y de la participación de las familias dentro de la escuela.

En cuanto a las estrategias metodológicas desarrolladas dentro del aula, se debe tener en cuenta el desarrollo de un tipo de enseñanza activa y constructiva, capaz de promover un tipo de aprendizaje significativo, elaborar tácticas de enseñanza atractivas que potencien la motivación e incrementen la capacidad de criterio y razonamiento, y ofrecer oportunidades de aprendizaje que permitan enriquecerse. Desarrollar estrategias que potencien e incrementen la motivación de todo el 
alumnado, no es una tarea fácil para el profesorado. No obstante, se ha comprobado por parte de numerosos autores como el desarrollo de estas actuaciones en el aula, lleva consigo un incremento de la iniciativa e interés por la realización de las actividades escolares, en muchos/as estudiantes. Cid (2008) defiende que son muy diversos los estudios que han comprobado como el uso de estrategias en el aula incrementa la propia motivación escolar. Así, es importante tener en cuenta que la enseñanza no debe concebirse como una simple transmisión de conocimiento, sino que ésta ha de ser entendida como una motivación académica, en la que se encuentre un aprendizaje significativo. (Pérez, 2001; Fiorini y Garcia-Ramirez, 2013)

La actuación docente, por su parte, juega un papel fundamental en el incremento de la motivación del aprendizaje del alumnado, en su rendimiento y sus resultados académicos. Esto se debe, esencialmente, a la influencia que ejercen sobre los estudiantes, al convivir junto a ellos un elevado número de horas al día. Este es el motivo principal por el que desde la propia escuela o instituto se debe proporcionar un ambiente de trabajo adecuado, en el que exista un clima de confianza y una actitud positiva, de cooperación y de ayuda mutua, no sólo entre los propios compañeros/as de clase, sino también entre éstos y los distintos profesores/as. Shaaban (2006) afirma así, que un contexto de aprendizaje cooperativo, fomenta la motivación intrínseca de los individuos.

Debido a que la cultura escolar que tienen los estudiantes de los colegios e institutos, no sólo se construye por medio de las numerosas experiencias compartidas que tienen con la propia comunidad educativa, sino también por la influencia de las expectativas familiares y las sociales se considera imprescindible destacar el papel de las familias en la potenciación de la motivación escolar de sus hijos e hijas. De forma que, su grado de participación en el aula, su colaboración en las tareas y actividades escolares o su apoyo emocional prestado, entre otros aspectos, influye en la educación y motivación del alumnado. (Fiorini y Garcia-Ramirez, 2013)

\section{La importancia de educar y motivar en una conciencia de valores:}

La relación existente entre los valores y la propia motivación de las personas, dentro de los contextos educativos, se encuentra en dos grandes aspectos: el valor como medio y el valor como meta (Casares, 2008). El primero, consiste en educar de acuerdo con aquellos valores que tienen las personas; valores que ya han sido vividos previamente por las mismas y actúan como desencadenantes de la propia motivación. De esta forma, si lo que se ofrece desde la escuela y el instituto coincide con algo que produce agrado y/o satisfacción personal, la conducta se activará y dirigirá hacia la consecución de las metas que han sido previamente propuestas; y el segundo, consiste en instruir con el objetivo o la finalidad de que las personas adquieran unos valores que aún no han experimentado a lo largo de su vida; se trata de valores que son pensados y pueden anticipar a la persona a resolver de forma determinada su identidad, autoconcepto y autoestima. Estos valores pueden convertirse en grandes motivos dentro de la vida de las personas, debido a que seducen al estimular los deseos latentes en el interior de los individuos y permiten evaluar la realidad de forma distinta y comprenderse a uno mismo de manera diferente. (Marina, 1998)

Otros autores como Touriñán (2008b) hablan de la relación entre los valores y la motivación por medio de la existencia de una educación en valores como tarea y como resultado. De forma que, considera que la primera es aquella que pretende que los individuos construyan su experiencia axiológica a partir de su aprendizaje y su interrelación con los valores; y la segunda, es aquella que trata de utilizar esa experiencia axiológica para construir y conformar su propio proyecto de vida y de 
identidad como personas. En este sentido, la motivación puede interpretarse como el resultado que se obtiene del propio descubrimiento de los valores (Bouché, 2005). Estas mismas características sobre la relación de los valores y la motivación quedan reflejadas en otros autores como Guaman (2013), quien basándose en la clasificación que Rokeach desarrolló dentro de su obra "The nature of human values" en el año 1973, diferenció la existencia de unos valores de tipo terminal e instrumental. Los primeros son aquellos que hacen referencia a aquellos que las personas quieren alcanzar a lo largo de su vida (amistad, aprecio, libertad, etc.), y los segundos a aquellos que implementan la conducta de las personas para acabar consiguiendo los valores terminales o fines deseados en la vida.

Los diferentes estudios realizados por estos autores, presentan la motivación intrínseca como la pieza clave y fundamental que impulsa a las personas hacia el logro de una serie de aspiraciones o metas concretas, vinculadas con el sentido interno de la realización y satisfacción personal, profundamente vinculada a los valores. En este sentido, se entiende que la motivación intrínseca tiene una fuerte implicación en las personas y en su propio bienestar personal, moral y social.

\section{MÉTODO}

Este estudio se realizó durante el curso académico 2013-2014, dentro de un Instituto de tipo público de la provincia de Granada, con el objetivo de analizar las necesidades existentes a nivel de valores en los alumnos y alumnas de Educación Secundaria Obligatoria, y con el fin de proporcionar una serie de orientaciones para la mejora de la Educación Moral de todos estos estudiantes.

\section{Centro educativo}

El Instituto en el que se va a llevar a cabo la investigación es un centro público de línea 2 que se encuentra ubicado en la zona norte de Granada. Se trata de un instituto que destaca por ser un centro TIC-2.0 y bilingüe (español-inglés), aunque para el próximo año se espera que se convierta en un centro plurilingüe (español-inglésalemán). En el mismo, estudian alrededor de 500 estudiantes, y se ofrecen estudios de E.S.O. Bachillerato y Ciclos Formativos de Grado Medio y Superior. Prácticamente la mitad de su alumnado de ESO y Bachiller procede del medio rural, especialmente de cinco pueblos muy cercanos de la zona; mientras que el resto de población estudiantil procede de tres pequeñas barriadas, situadas junto al centro. En el caso de los Ciclos Formativos la procedencia del alumnado es más heterogénea, siendo mayoritario el número de estudiantes procedentes de la propia provincia de Granada. Además, la proximidad del instituto a centros pertenecientes a ONGs, que dan acogida a diversos jóvenes procedentes de familias desestructuradas o jóvenes inmigrantes tutelados por la Junta de Andalucía, hace que una pequeña parte del alumnado del centro proceda de este tipo de instituciones. En el curso académico 2013-2014 hay matriculados en el centro un elevado número de estudiantes, procedentes de una veintena de nacionalidades diferentes.

\section{Participantes}

En este estudio han participado voluntariamente 147 alumnos/as de los cuatro cursos de Educación Secundaria Obligatoria, con unas edades comprendidas entre los 12 y 18 años. Las principales características de los grupos que integran estos cursos son los siguientes: 
- El curso $1^{\circ}$ ESO A, se encuentra conformado por 23 estudiantes con una edad comprendida entre los 12 y13 años. De estos alumnos/as 15 son chicas y 8 son chicos. El 40,9\% de estos estudiantes son de Granada capital, el 36,3\% de tres pueblos cercanos a la zona, y el $22,7 \%$ de otras provincias andaluzas como Almería y Cádiz, y países como Argentina y Rumanía.

- El curso $1^{\circ}$ ESO B, se encuentra conformado por 22 estudiantes con una edad comprendida entre los 12 y 13 años. De estos alumnos/as 11 son chicas y 11 son chicos. El 22,7\% de estos estudiantes son de Granada capital, el 36,3\% de dos pueblos cercanos de la zona, y el $40,9 \%$ de otras provincias andaluzas como Almería y Jaén, ciudades españolas como Barcelona, y ciudades estadounidenses como Chicago.

- El curso $2^{\circ}$ ESO A, se encuentra conformado por 21 estudiantes con una edad comprendida entre los 13 y 15 años. De estos alumnos/as 9 son chicas y 12 son chicos. El $19 \%$ de estos estudiantes son de Granada capital, el $66,5 \%$ de tres pueblos de la zona, y el $14,2 \%$ de otras ciudades españolas como La Rioja, y otros países como EE.UU e Irlanda.

- El curso $2^{\circ}$ ESO B, se encuentra conformado por 21 estudiantes con una edad comprendida entre los 13 y 15 años. De estos alumnos/as 9 son chicas y 12 son chicos. El 23,8\% de estos estudiantes son de Granada capital, el 66,6\% de dos pueblos de la zona, y el $9,5 \%$ de otras ciudades como New Jersey (EEUU) y Santiago de Chile (Chile).

- El curso $3^{\circ}$ ESO A, se encuentra conformado por 21 estudiantes con una edad comprendida entre los 14 y 16 años. De estos alumnos/as 11 son chicas y 10 son chicos. El 23,8\% de estos estudiantes son de Granada capital, el 61,8 son de dos pueblos de la zona, y el $14,2 \%$ de otra serie de provincias andaluzas como Sevilla y Jaén.

- El curso $3^{\circ}$ ESO B, se encuentra conformado por 17 estudiantes con una edad comprendida entre los 14 y 15 años. De estos alumnos/as 11 son chicas y 6 son chicos. El $43,7 \%$ de estos estudiantes son de Granada capital, el 49,9\% son de cuatro pueblos de la zona, y el $6,2 \%$ de otras ciudades españolas como Girona.

- El curso $4^{\circ}$ ESO A, se encuentra conformado por 19 estudiantes con una edad comprendida entre los 15 y 18 años. De estos alumnos/as 8 son chicas y 11 son chicos. El $26,3 \%$ de estos estudiantes son de Granada capital, el $78,9 \%$ son de dos pueblos de la zona, y el $5,2 \%$ de otras ciudades como Rusia.

- El curso $4^{\circ}$ ESO B, se encuentra conformado por 31 estudiantes con una edad comprendida entre los 15 y los 17 años. De estos alumnos/as 16 son chicas y 15 son chicos. El 48,3\% de estos estudiantes son de Granada capital, el $25,7 \%$ de dos pueblos de la zona, el 3,2\% de Motril, y el $12,9 \%$ de otras provincias andaluzas como Cádiz, otras ciudades españolas como Murcia, y otros países como Colombia, Cuba, Austria y Suiza.

\section{Instrumentos}

Para evaluar las necesidades de Educación en Valores existentes en los alumnos/as de Educación Secundaria Obligatoria del centro educativo, además de hacer uso de los documentos propios del instituto como el Plan de Acción Tutorial o el Plan de Convivencia, se pasó un cuestionario de dos ítems de respuestas abiertas por medio del cual se mide el grado de conocimiento que tienen los estudiantes sobre el concepto de "valor", así como el número de valores que son capaces de recordar.

\section{Procedimiento}

Para la realización de la presente investigación se ha llevado a cabo, en primer lugar, una revisión bastante exhaustiva de la documentación del centro que ha sido 
anteriormente descrito y, en segundo lugar, una observación durante seis semanas de los alumnos y alumnas de Educación Secundaria Obligatoria y las necesidades existentes entre ellos. De todo ello, se ha comprobado lo siguiente:

1. A nivel de documentación de centro, el instituto cuenta con un Proyecto Educativo de Centro en el que vienen recogidos, además de los valores democráticos en funcionamiento en el mismo, una serie de medidas referentes a la educación en valores; formando parte del Plan de Acción Tutorial y el Plan Convivencia.

El Plan de Acción Tutorial del centro asume, entre la programación de sus actividades, los fines perseguidos por el sistema educativo español, recogidos en el artículo 2 de la LOE. Entre estos fines se estacan los que hacen referencia a la educación en el respeto de los derechos y libertades fundamentales, y la igualdad de derechos y oportunidades sin ningún tipo de discriminación; la educación en los valores de tolerancia, libertad, cooperación, solidaridad, respeto a los seres vivos y medio ambiente; la educación para la paz y el respeto de los derechos humanos, la vida en común y la cohesión social, así como en la prevención de los conflictos y la resolución pacífica de los mismos; y el respeto a la propia interculturalidad como un elemento enriquecedor de la sociedad. No obstante, sólo recogen formalmente como actividades o tareas que se deben desempeñar en horario de tutoría, las destinadas al Proyecto Hombre y Programa Forma Joven, cuyos contenidos no son propiamente de educación en valores, sino de educación para una vida saludable. De forma controvertida, se recoge fuera de la programación del propio Plan de Acción Tutorial, un listado demasiado amplio de tutorías que el orientador u orientadora del centro, en el que se ha llevado a cabo la investigación, viene aportando todas las semanas a los tutores y tutoras de cada curso y grupo de Educación Secundaria Obligatoria, pero de las cuales no tiene ningún tipo de certeza ni de garantía de que se lleguen a elaborar o lleven a la práctica. Uno de los aspectos que más llama la atención, a simple vista del mismo, es que a pesar de las numerosas tutorías que se proponen para cada uno de los cursos durante los tres trimestres, las relacionadas con la educación en valores son mínimas frente al resto, pese a la importancia que se le otorga a la educación moral dentro del Proyecto Educativo de Centro.

Tabla 1. Tutorías de Educación en valores en el IES

\begin{tabular}{ll}
\hline Curso & Tutorías de Educación en Valores \\
\hline De $1^{\circ}$ de ESO & Sólo seis tutorías de treinta y dos planificadas \\
De $2^{\circ}$ de ESO & Sólo dos tutorías de treinta y dos planificadas \\
De $3^{\circ}$ de ESO & Sólo tres tutorías de treinta y dos planificadas \\
De $4^{\circ}$ de ESO & Sólo tres tutorías de treinta y dos planificadas \\
\hline
\end{tabular}

El Plan de Convivencia del centro, dirigido a la atención y corrección de las diferentes conductas problemáticas existentes, tiene como principal objetivo dar respuesta a los problemas de convivencia que, según los registros recogidos durante varios años en el programa Séneca, se centran en el conjunto de las actuaciones incorrectas que se realizan hacia algún miembro de la propia comunidad educativa, la falta de colaboración sistemática en torno a la realización de las actividades y la perturbación del normal desarrollo de las tareas escolares. Para dar respuesta a las conductas contrarias de convivencia, el instituto ha optado por la elaboración de una serie de actividades, como la celebración del Día Escolar de la Paz, el Día de la Mujer Trabajadora, etc., el establecimiento de una serie de normas de conducta a nivel de aula y centro, y la creación de un Aula específica de Convivencia, como un espacio propio de reflexión, de arrepentimiento, de establecimiento de compromisos, de trabajo individualizado, etc. No obstante y a pesar de las diversas medidas empleadas, se ha 
observado que son muy pocas las tareas o actividades que se realizan para trabajar los valores desde el centro, y se ha evidenciado la presencia de dos tipos de problemas dentro del Aula de Convivencia: la ausencia de medidas para trabajar el conjunto de valores morales y democráticos entre el alumnado, como principios para conseguir un clima de buena convivencia y para la reeducación de las conductas problemáticas; y la preferencia por la expulsión de los alumnos/as al pasillo, en vez de su destino a esta aula.

2. A nivel de la observación realizada en el centro, durante un periodo de seis semanas, se destaca la presencia de diversos insultos por parte del alumnado y alguna pelea, las faltas de respeto hacia los compañeros/as y profesorado (hablar sin pedir el turno de palabra, interrumpir mientras habla alguien, levantarse del asiento sin pedir permiso, molestar durante el desarrollo de una clase o hablar constante en la misma, entre otros aspectos importantes), las faltas de respeto hacia las propias creencias o pensamientos religiosos y/o políticos, la presencia de un comportamiento problemático dentro de la propia clase (hablar a gritos o voces, molestar a los compañeros/as o al profesor/a, tirar papeles, jugar con el móvil o chatear por las diferentes redes sociales, etc.), y la presencia de ciertos comentarios referentes a la inferioridad de las mujeres. Todos estos comportamientos observados, de forma general, en el alumnado han derivado en la presencia de distintos partes de convivencia y expulsiones en el centro; y en la existencia de un caso de acoso escolar iniciado en el aula y continuado a través de las redes sociales, entre varias alumnas del instituto.

3. A nivel de alumnado de Educación Secundaria Obligatoria del centro, se ha llevado a cabo la elaboración de un estudio de carácter exploratorio y cualitativo, que ha manifestado la necesidad de implementar una serie de orientaciones para la mejora de la Educación en Valores de los alumnos y alumnas de Educación Secundaria Obligatoria del centro. Esta información ha sido obtenida a partir del análisis realizado sobre las respuestas aportadas por los estudiantes, en un cuestionario de preguntas abiertas que se les ha pasado, y en el cual se ha medido su grado de conocimiento acerca del concepto "valor", así como el número de valores que conocen o son capaces de recordar.

A continuación se muestran los datos obtenidos del cuestionario de respuestas abiertas: El alumnado participante ha sido de 147 niños/as de edades comprendidas entre los 12 y 18 años. A continuación se muestran las tablas y gráficas con los datos obtenidos, indicando la frecuencia y porcentajes, referentes a la edad, género, grupo, concepto y valores conocidos. Posteriormente se mostrarán las tablas de contingencias.

Tabla 2: Frecuencia de estudiantes en función de la edad

\begin{tabular}{rrrr}
\hline & & Frecuencia & Porcentaje \\
\hline \multirow{6}{*}{ Válidos } & 12 & 22 & 15,0 \\
& 13 & 39 & 26,5 \\
& 14 & 34 & 23,1 \\
& 15 & 32 & 21,8 \\
& 16 & 16 & 10,9 \\
& 17 & 3 & 2,0 \\
& 18 & 1 &, 7 \\
\cline { 2 - 4 } & Total & 147 & 100,0 \\
\hline
\end{tabular}

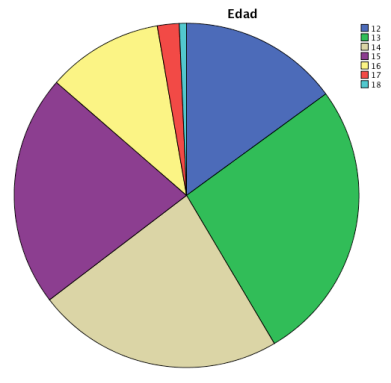

Figura 1: Porcentaje de estudiantes en función de la edad 
Tabla 3: Frecuencia en función del género

\begin{tabular}{rlrr}
\hline & & Frecuencia & Porcentaje \\
\hline \multirow{3}{*}{ Válidos } & Hombre & 73 & 49,7 \\
& Mujer & 74 & 50,3 \\
\cline { 2 - 4 } & Total & 147 & 100,0 \\
\cline { 2 - 4 }
\end{tabular}

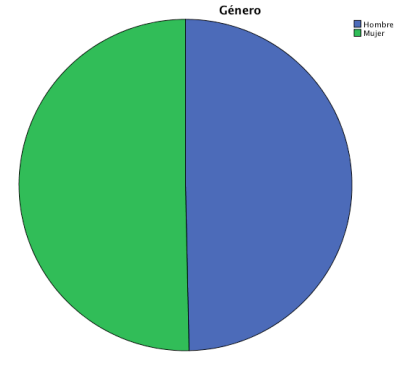

Figura 2: Porcentaje en función del género

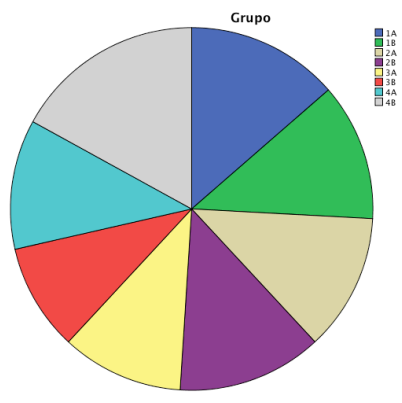

Figura 3: Porcentaje de participación por grupo

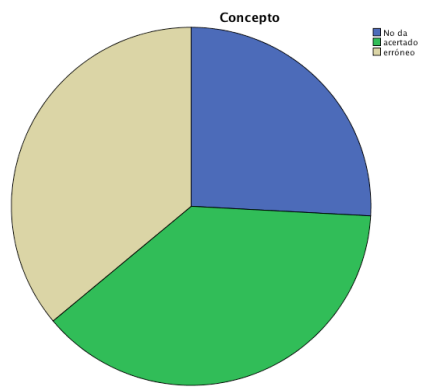

Figura 4: Porcentaje de respuestas del concepto de valor

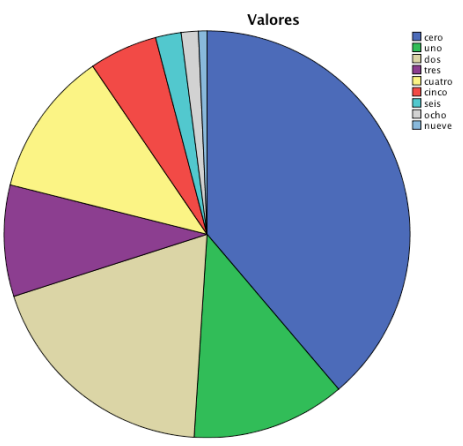

Figura 5: Porcentaje de valores
Tabla 6: Frecuencia de valores

\begin{tabular}{|c|c|c|c|}
\hline & & Frecuencia & Porcentaje \\
\hline \multirow{10}{*}{ Válidos } & Cero & 57 & 38,8 \\
\hline & Uno & 18 & 12,2 \\
\hline & Dos & 28 & 19,0 \\
\hline & Tres & 13 & 8,8 \\
\hline & Cuatro & 17 & 11,6 \\
\hline & Cinco & 8 & 5,4 \\
\hline & Seis & 3 & 2,0 \\
\hline & Ocho & 2 & 1,4 \\
\hline & Nueve & 1 &, 7 \\
\hline & & 147 & 100,0 \\
\hline
\end{tabular}

Tabla 5: Frecuencia de respuestas del concepto de valor

\begin{tabular}{rlrr}
\hline & & Frecuencia & Porcentaje \\
\hline \multirow{4}{*}{ Válidos } & No da & 38 & 25,9 \\
& concepto & & 38,1 \\
& Acertado & 56 & 36,1 \\
\cline { 2 - 4 } & Erróneo & 53 & 100,0 \\
\cline { 2 - 4 } & \multicolumn{1}{r}{ Total } & 147 &
\end{tabular}

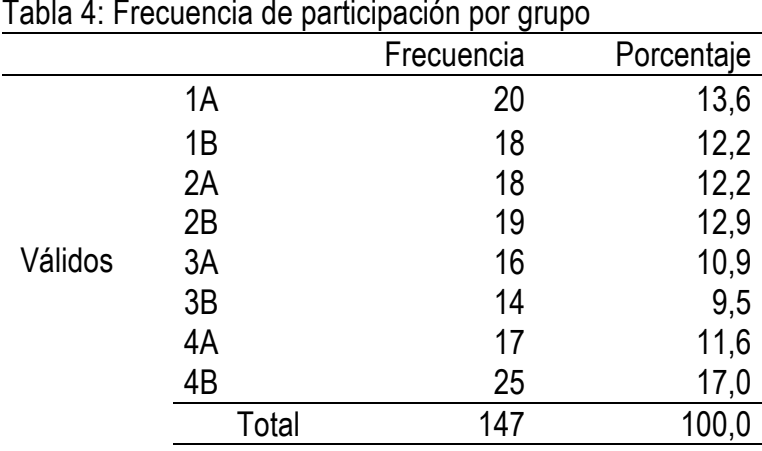




\section{Tablas de contingencias}

Los datos reflejados a través de la tabla 7 y figura 6 muestran que el alumnado del IES que mayoritariamente conoce el concepto de valor, es el grupo de $4^{\circ}$ de ESO B. A este grupo le siguen otros como $3^{\circ}$ de ESO B, $1^{\circ}$ de ESO B, $4^{\circ}$ de ESO A. Por el contrario el resto de grupos, presentan un conocimiento muy bajo de este concepto.

Tabla 7: Frecuencia concepto por grupos

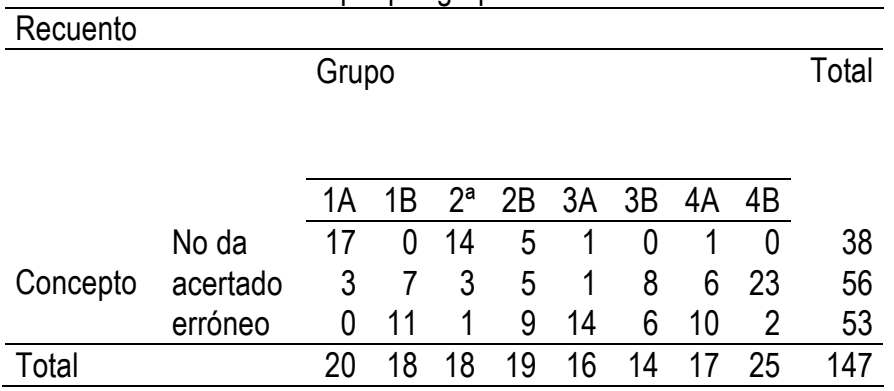

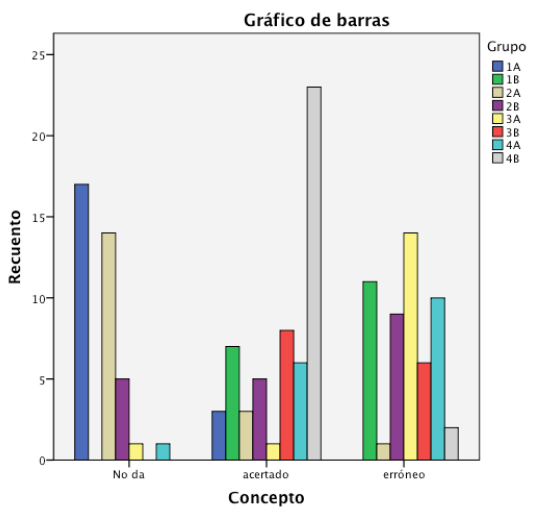

Figura 6: Frecuencia de concepto por grupos

La prueba de Chi-cuadrado en la tabla de contingencias es de 131,433 (Sig. Asintótica de 0.00), lo que demuestra estadísticamente que hay diferencias significativas entre el grupo y el concepto de valor.

Los datos reflejados a través de la tabla 8 y figura 7 muestran que el alumnado del IES que conoce más valores, con diferencia, (superior a un número de cinco) es el grupo $3^{\circ}$ y $4^{\circ} \mathrm{ESO} \mathrm{B}$. Mientras que los grupos que más desconocimiento tienen sobre los valores existentes (no superior a un número de tres) son los de $1^{\circ} \mathrm{ESO} \mathrm{A}, 2^{\circ} \mathrm{ESO} \mathrm{A}$, $3^{\circ} \mathrm{ESO}$ A y $4^{\circ} \mathrm{ESO}$ A.

\begin{tabular}{|c|c|c|c|c|c|c|c|c|c|c|}
\hline \multicolumn{11}{|c|}{ Recuento } \\
\hline & & \multicolumn{8}{|c|}{ Grupo } & \multirow[t]{2}{*}{ Total } \\
\hline & & $1 \mathrm{~A}$ & $1 \mathrm{~B}$ & $2 A$ & $2 B$ & $3^{a}$ & $3 B$ & $4 \mathrm{~A}$ & $4 B$ & \\
\hline & Cero & 14 & 2 & 17 & 0 & 13 & 2 & 9 & 0 & 57 \\
\hline & Uno & 4 & 6 & 0 & 0 & 2 & 0 & 3 & 3 & 18 \\
\hline & Dos & 1 & 5 & 1 & 3 & 1 & 5 & 5 & 7 & 28 \\
\hline & Tres & 1 & 1 & 0 & 5 & 0 & 3 & 0 & 3 & 13 \\
\hline \multirow[t]{5}{*}{ Valores } & Cuatro & 0 & 3 & 0 & 11 & 0 & 2 & 0 & 1 & 17 \\
\hline & Cinco & 0 & 1 & 0 & 0 & 0 & 2 & 0 & 5 & 8 \\
\hline & Seis & 0 & 0 & 0 & 0 & 0 & 0 & 0 & 3 & 3 \\
\hline & Ocho & 0 & 0 & 0 & 0 & 0 & 0 & 0 & 2 & 2 \\
\hline & Nueve & 0 & 0 & 0 & 0 & 0 & 0 & 0 & 1 & 1 \\
\hline Total & & 20 & 18 & 18 & 19 & 16 & 14 & 17 & 25 & 147 \\
\hline
\end{tabular}

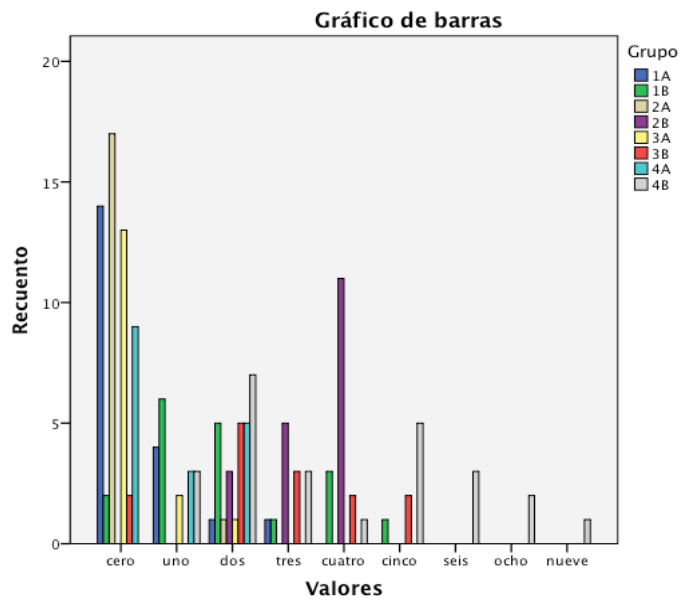

Figura 7: Frecuencia de valores por grupos

La prueba de Chi-cuadrado en la tabla de contingencias es de 180,282 (Sig. Asintótica de 0.00 ) lo que demuestra estadísticamente que hay diferencias significativas entre el grupo y la frecuencia de los valores. 


\section{Análisis cualitativo de las respuestas dadas al concepto de valor}

Por otra parte, se ha realizado un análisis de categorización de la información recogida de la primera pregunta del instrumento de evaluación. Con este análisis se ha tratado de conocer las diferentes necesidades de Valores existentes entre los estudiantes. Dicha información ha sido evaluada de acuerdo al grado de madurez y presentada de forma individual en función del grupo pertenencia $\left(1^{\circ}, 2^{\circ}, 3^{\circ} \circ 4^{\circ}\right)$ y la modalidad $(A$ y $B$ ). Las respuestas consideradas "Más próximas" (correctas) han sido aquellas que han recogido algún aspecto clave y/o esencial de lo que significan los valores, mientras que las respuestas "Más alejadas" (incorrectas) han sido aquellas que se han desviado de la cuestión o han resultado ambiguas o incompletas para la edad y madurez. El análisis realizado ha sido el siguiente:

Del grupo $1^{\circ} \mathrm{A}$ sólo han contestado a la definición de Valores tres estudiantes de veinte. Todas las contestaciones han sido consideradas correctas. En la tabla que se expone a continuación se muestran las respuestas.

Tabla 9: Respuestas del grupo $1^{\circ} \mathrm{ESO} A$

\begin{tabular}{lll}
\hline Curso $1^{\circ} \mathrm{A}$ & Respuestas más próximas & Respuestas más alejadas \\
\hline & Yo creo que los valores es lo que tú valoras, las cosas importantes. $\left(1^{*}\right)$ & \\
\hline & Son las cualidades de una persona. $\left(2^{*}\right)$ & \\
\hline
\end{tabular}

* (n) Frecuencia

Del grupo $1^{\circ} \mathrm{B}$ han contestado a la definición de Valores, todos los alumnos/as de clase, es decir, los dieciocho estudiantes que conforman la misma. De las respuestas ofrecidas por los alumnos/as o sólo siete son consideradas correctas o más próximas a la propia definición real, por recoger o incluir algunos aspectos claves y esenciales de la misma; mientras que once de las respuestas aportadas son consideradas incorrectas o más alejadas a la definición real, por incluir ciertos contenidos que se desvían de esta temática o por ser consideradas ambiguas y bastante escuetas. En la tabla que se expone a continuación se muestran todas las respuestas.

Tabla 10: Respuestas del grupo $1^{\circ} \mathrm{ESO} \mathrm{B}$

\begin{tabular}{|c|c|c|}
\hline Curso $1^{\circ} \mathrm{B}$ & Respuestas más próximas & Respuestas más alejadas \\
\hline & $\begin{array}{l}\text { Son las cosas importantes de tu vida y que tienen } \\
\text { valor para nosotros. }\left(2^{\star}\right)\end{array}$ & \\
\hline & $\begin{array}{l}\text { Son cosas que tienen valor para nosotros y que son } \\
\text { muy importantes personalmente. }\left(1^{*}\right)\end{array}$ & \\
\hline & $\begin{array}{l}\text { Es aquello que es importante para ti. Lo más } \\
\text { importante para tu vida. }\left(1^{\star}\right)\end{array}$ & \\
\hline & & Lo que apreciamos, lo que nos interesa. $\left(1^{*}\right)$ \\
\hline & & $\begin{array}{l}\text { La amistad sirve para tener más vida social; el saber } \\
\text { te sirve para aprender; la familia, para contarles tus } \\
\text { problemas, etc. }\left(1^{*}\right)\end{array}$ \\
\hline & $\begin{array}{l}\text { Sirven para tener más vida social y para unirnos más a } \\
\text { todos. }\left(1^{*}\right)\end{array}$ & \\
\hline & $\begin{array}{l}\text { Son cosas que te describen, que describen tu } \\
\text { personalidad. }\left(1^{*}\right)\end{array}$ & \\
\hline & & $\begin{array}{l}\text { El valor de mi vida es que hablo tres lenguas y tengo } \\
\text { sólo } 13 \text { años. }\left(1^{\star}\right)\end{array}$ \\
\hline & & Son cosas a lo que le das importancia. $\left(2^{*}\right)$ \\
\hline & & Son cosas que te importan más o menos. $\left(1^{*}\right)$ \\
\hline & & $\begin{array}{l}\text { Es algo que tú haces y tienes, para enfrentarte a las } \\
\text { situaciones. }\left(1^{*}\right)\end{array}$ \\
\hline & $\begin{array}{l}\text { Es una enseñanza que nos trasmite algo y a la que } \\
\text { nosotros damos importancia. }\left(1^{*}\right)\end{array}$ & \\
\hline & & Lo que te sirve. $\left(1^{*}\right)$ \\
\hline & & Algo que tú valoras. $\left(3^{*}\right)$ \\
\hline
\end{tabular}

${ }^{*}(\mathrm{n})$ Frecuencia

Lo que te sirve. $\left(1^{*}\right)$ 
Del grupo $2^{\circ} \mathrm{A}$ sólo han contestado a la definición de Valores cuatro de los dieciocho estudiantes que conforman el grupo clase. De las respuestas aportadas por este reducido número de alumnos/as, tres son consideradas correctas o próximas a la definición real, aunque bastante breves; mientras que la otra es considerada incorrecta o alejada a la definición, por tener una idea equivocada acerca de la misma, véase la siguiente tabla.

Tabla 11: Respuestas del grupo $2^{\circ}$ ESO A

\begin{tabular}{lll}
\hline Curso $2^{\circ} \mathrm{A}$ & Respuestas más próximas & Respuestas más alejadas \\
\hline & $\begin{array}{l}\text { Lo que las otras personas piensan de ti y lo } \\
\text { bueno que te ves. }\left(1^{*}\right)\end{array}$ \\
\hline & $\begin{array}{l}\text { Una serie de principios que tienen las personas y que } \\
\text { varian según las mismas. }\left(1^{*}\right)\end{array}$ \\
\hline & Son las cualidades de las personas. $\left(2^{*}\right)$ & \\
\hline${ }^{*}(\mathrm{n})$ Frecuencia &
\end{tabular}

Del grupo $2^{\circ} \mathrm{B}$ sólo han respondido a la definición de Valores catorce de los diecinueve alumnos/as de la clase. De las respuestas ofrecidas por estos estudiantes cinco son consideradas correctas o próximas a la definición real, por incluir algún aspecto característico de la misma; y nueve, son consideradas incorrectas o alejadas a esta definición, por tener una idea equívoca y por ser demasiado concisas en la conceptualización. En la tabla que se expone a continuación se recogen las respuestas.

Tabla 12: Respuestas del grupo $2^{\circ} \mathrm{ESO} B$

\begin{tabular}{|c|c|c|}
\hline Curso $2^{\circ} \mathrm{B}$ & Respuestas más próximas & Respuestas más alejadas \\
\hline & & $\begin{array}{l}\text { Puede tener muchos significados como, por } \\
\text { ejemplo, la igualdad, la convivencia, etc. }\left(1^{*}\right)\end{array}$ \\
\hline & $\begin{array}{l}\text { Los valores son las cosas que hace o tiene cada } \\
\text { persona, para ser buena persona, educada y feliz } \\
\text { consigo mismo y con los demás. }\left(1^{*}\right)\end{array}$ & \\
\hline & & $\begin{array}{l}\text { Depende, esta palabra tiene muchos significados } \\
\text { como, por ejemplo, igualdad, colaboración, } \\
\text { convivencia, etc. }\left(1^{*}\right)\end{array}$ \\
\hline & & $\begin{array}{l}\text { Son sentimientos o realidades que dependen de } \\
\text { nuestra voluntad o de la de otros. }\left(1^{*}\right)\end{array}$ \\
\hline & & $\begin{array}{l}\text { Son sentimientos y acciones que nosotros podemos } \\
\text { realizar. }\left(1^{*}\right)\end{array}$ \\
\hline & & Son objetos que valen para ti (el precio de algo). $\left(1^{*}\right)$ \\
\hline & $\begin{array}{l}\text { Son las cosas buenas que nos influyen a nosotros } \\
\text { mismos. }\left(1^{*}\right)\end{array}$ & \\
\hline & & $\begin{array}{l}\text { Son acciones que nos ayudan física } y \\
\text { primariamente. }\left(1^{*}\right)\end{array}$ \\
\hline & & Es el sentimiento que tenemos hacia alguien. $\left(1^{*}\right)$ \\
\hline & $\begin{array}{l}\text { Son las cosas que hacen que una persona sea buena, } \\
\text { respetada y libre. }\left(1^{*}\right)\end{array}$ & \\
\hline & Son aquellos que te enseñan a ser mejor persona. $\left(1^{*}\right)$ & \\
\hline & & Lo que se piensa, lo que está bien hecho. $\left(1^{*}\right)$ \\
\hline & & Son aptitudes. $\left(1^{*}\right)$ \\
\hline & $\begin{array}{l}\text { Son aquellos que te hacen único, y nunca debes } \\
\text { renunciar a ellos por nada ni nadie. }\left(1^{*}\right)\end{array}$ & \\
\hline
\end{tabular}

${ }^{*}(\mathrm{n})$ Frecuencia

Del grupo $3^{\circ} \mathrm{A}$ han respondido a la definición de Valores quince de los dieciséis niños y niñas de la clase. De todas las respuestas aportadas por estos alumnos/as todas son consideradas incorrectas o alejadas del término Valor, excepto una que por las particularidades y aspectos que clave que presenta ha sido considerada correcta. En la tabla que se expone a continuación se recogen las respuestas presentadas por los diversos estudiantes. 
Tabla 13: Respuestas del grupo $3^{\circ} \mathrm{ESO} \mathrm{A}$

\begin{tabular}{|c|c|c|}
\hline Curso $3^{\circ} \mathrm{A}$ & Respuestas más próximas & Respuestas más alejadas \\
\hline & & $\begin{array}{l}\text { Son cosas o situaciones que significan algo para mí, sean materiales } \\
\text { (dinero) como no materiales (sentimientos). }\left(1^{*}\right)\end{array}$ \\
\hline & & $\begin{array}{l}\text { Son las cosas que haces. Cosas importantes para ti. Ejemplo: ver a } \\
\text { mi novio, tener un coche, etc. }\left(1^{*}\right)\end{array}$ \\
\hline & & Es algo que se debe hacer. $\left(1^{*}\right)$ \\
\hline & & $\begin{array}{l}\text { Son las cosas importantes para una persona como, por ejemplo, el } \\
\text { que me quieran los chicos, o el tener unos estudios para ser alguien } \\
\text { en el futuro. }\left(1^{*}\right)\end{array}$ \\
\hline & $\begin{array}{l}\text { Enseñanzas que nos enseñan los } \\
\text { padres cuando vamos creciendo para } \\
\text { tener educación. }\left(1^{*}\right)\end{array}$ & \\
\hline & & Son el esfuerzo que haces por lo que deseas. $\left(1^{*}\right)$ \\
\hline & & Son las cosas que deseas y que consigues con esfuerzo. $\left(1^{*}\right)$ \\
\hline & & $\begin{array}{l}\text { Son las cosas buenas que tiene cada uno, los gustos, aficiones, } \\
\text { sentimientos, pensamientos, etc. }\left(1^{*}\right)\end{array}$ \\
\hline & & $\begin{array}{l}\text { Es el esfuerzo, las promesas, las ganas que le pones a algo que } \\
\text { quieres o te atrae. }\left(1^{\star}\right)\end{array}$ \\
\hline & & $\begin{array}{l}\text { Son las obligaciones que tenemos que hacer o cumplir, que nos } \\
\text { ponemos nosotros mismos para el bien de nosotros. }\left(1^{*}\right)\end{array}$ \\
\hline & & Lo que los padres te enseñan. $\left(1^{*}\right)$ \\
\hline & & $\begin{array}{l}\text { Son las cosas que quieres en un futuro, por ejemplo, estar centrado } \\
\text { en tu vida. }\left(1^{*}\right)\end{array}$ \\
\hline & & $\begin{array}{l}\text { Son lo que las personas valoramos, es decir lo que queremos en } \\
\text { nuestra vida. }\left(1^{*}\right)\end{array}$ \\
\hline & & Son importantes, independientemente para las personas. $\left(2^{*}\right)$ \\
\hline
\end{tabular}

${ }^{*}(\mathrm{n})$ Frecuencia

Del grupo $3^{\circ} \mathrm{B}$, han respondido todos/as. Ocho respuestas han sido consideradas correctas; mientras que seis han sido consideradas incorrectas. En la tabla que se expone a continuación se recogen las respuestas presentadas.

Tabla 14: Respuestas del grupo $3^{\circ} \mathrm{ESO} \mathrm{B}$

\begin{tabular}{lll}
\hline Curso $3^{\circ} \mathrm{B}$ & Respuestas más próximas & Respuestas más alejadas \\
\hline & Son los actos que una persona hace y que, por tanto, la \\
& representan como persona en sí. $\left(1^{*}\right)$ \\
\hline & Son algo moral, como el valor del respeto, amistad, \\
& solidaridad, educación, etc. $\left(1^{*}\right)$ & \\
& Es algo que nos ayuda a tomar las decisiones, y nos definen \\
& como personas. Cada uno tiene los suyos propios. $\left(1^{*}\right)$ \\
\hline & Son las cosas con importancia de la vida, lo mínimo que \\
& debemos saber, lo que hay que apreciar de una persona, de \\
& la vida misma. $\left(1^{*}\right)$ \\
\hline & Son los pilares sobre los que se basan nuestras acciones. Es \\
& decir, tú actúas de una manera u otra según tus valores. $\left(1^{*}\right)$ \\
\hline
\end{tabular}

En la vida hay que tener valores para saber elegir la opción correcta o la que parezca más apropiada. $\left(1^{\star}\right)$

Las distintas capacidades de algo, tanto bueno como malo. $\left(1^{*}\right)$

Son las cualidades que definen la personalidad y la forma de ser de una persona. Suelen ser cosas positivas. $\left(1^{*}\right)$

Son todas aquellas cosas que los padres te enseñan. $\left(1^{*}\right)$

Son algo imprescindible, se deben saber y respetar. $\left(1^{*}\right)$

Son tus pensamientos. Por los que nunca cambias de opinión. $\left(1^{*}\right)$

Son las enseñanzas que aprende una persona. (1*)

Es la voluntad que se nos da para tomar decisiones. $\left(1^{*}\right)$

\footnotetext{
* $(n)$ Frecuencia
}

Son las cualidades que tiene cada persona. $\left(1^{\star}\right)$ 
Del grupo $4^{\circ} \mathrm{A}$, han respondido a la definición de Valores todos los alumnos/as de clase, a excepción de uno. Es decir, dieciséis de los diecisiete estudiantes que conforman la misma. De las respuestas otorgadas por estos niños y niñas seis han sido consideradas acertadas o próximas a la definición, por tener una idea básica de los mismos; y diez han sido consideradas erróneas o alejadas de la misma, por presentar una idea equivocada sobre los valores o por ser demasiado pobres y breves. En la tabla que se expone a continuación se muestran las respuestas ofrecidas por los distintos estudiantes.

Tabla 15: Respuestas del grupo $4^{\circ}$ ESO A

\begin{tabular}{|c|c|c|}
\hline Curso $4^{\circ} \mathrm{A}$ & Respuestas más próximas & Respuestas más alejadas \\
\hline & $\begin{array}{l}\text { Son las cualidades que tienen las personas y la } \\
\text { manera con que las identificamos. }\left(2^{*}\right)\end{array}$ & \\
\hline & & Son los sentimientos que tienen las personas. $\left(2^{*}\right)$ \\
\hline & & $\begin{array}{l}\text { El valor de vivir, el valor de tener una familia que te } \\
\text { quiere, el valor de tener la oportunidad de aprender, etc. } \\
\left(1^{\star}\right)\end{array}$ \\
\hline & & $\begin{array}{l}\text { Es la importancia o precio que tienen las cosas, } \\
\text { sentimientos u objetos. }\left(1^{*}\right)\end{array}$ \\
\hline & $\begin{array}{l}\text { Es el conjunto de ideas que nos ayudan a tomar } \\
\text { las decisiones y cada uno tiene sus propios } \\
\text { valores y éstos van cambiando a lo largo de } \\
\text { nuestra vida. }\left(1^{*}\right)\end{array}$ & \\
\hline & $\begin{array}{l}\text { Es el conjunto de aspectos que puede tener una } \\
\text { persona (humildad, honestidad, etc.). }\left(1^{*}\right)\end{array}$ & \\
\hline & & $\begin{array}{l}\text { Lo que valoramos, hay valores sentimentales, materiales, } \\
\text { etc. El valor que le damos a algo o alguien. }\left(1^{*}\right)\end{array}$ \\
\hline & & El valor de las cosas, el valor de las personas, etc. $\left(1^{*}\right)$ \\
\hline & & $\begin{array}{l}\text { Son algo que no podemos explicar con cantidad, aunque } \\
\text { tienen un valor para nosotros. }\left(1^{*}\right)\end{array}$ \\
\hline & & Es la capacidad que te ayuda a resolver las cosas. $\left(1^{\star}\right)$ \\
\hline & Lo que apreciamos nosotros mismos. $\left(1^{*}\right)$ & \\
\hline & & $\begin{array}{l}\text { Son las ideas, pensamientos, sentimientos, que tiene } \\
\text { cada persona. }\left(1^{*}\right)\end{array}$ \\
\hline & $\begin{array}{l}\text { Es aquello que transmiten las personas } 0 \\
\text { entidades, como la humildad, el respeto hacia los } \\
\text { demás. Ejemplo el real Madrid transmite el valor } \\
\text { de no rendirse nunca, etc. }\left(1^{*}\right)\end{array}$ & \\
\hline & & $\begin{array}{l}\text { Son aquellos objetivos que se consiguen en la vida } \\
\text { cotidiana y a los que se le da una gran importancia. }\left(1^{*}\right)\end{array}$ \\
\hline
\end{tabular}

Del grupo $4^{\circ} \mathrm{B}$, han respondido a la definición de Valores todos los alumnos/as de clase. Es decir, los veinticinco estudiantes que constituyen la misma. De las respuestas otorgadas por estos niños y niñas veintitrés han sido consideradas acertadas o próximas a la definición, por la cantidad de información aportada, clave y específica de este concepto; mientras que dos de ellas han sido consideradas incorrectas o erróneas por no recoger aspectos esenciales de esta cuestión y tener una grave confusión acerca de este término. Este ha sido el grupo que ha presentado un mayor porcentaje de respuestas acertadas, de todos los que constituyen la ESO. En la tabla que se expone a continuación se muestran las respuestas ofrecidas por los diferentes estudiantes. 
Tabla 16: Respuestas del grupo $4^{\circ}$ ESO B

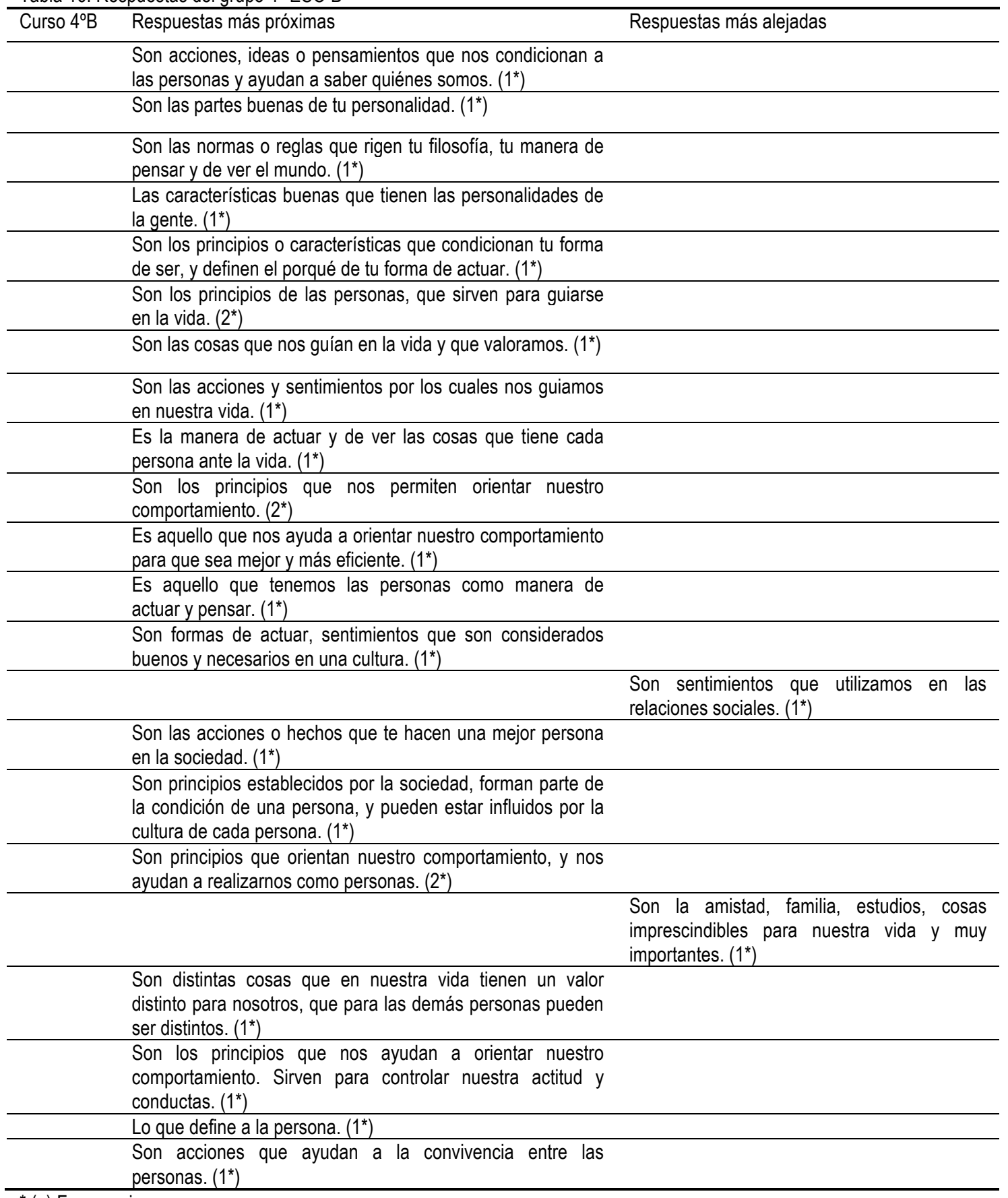

* (n) Frecuencia

\section{RESULTADOS}

Los resultados obtenidos a nivel cualitativo de la primera pregunta del cuestionario, instrumento de evaluación, para recoger información sobre el conocimiento presente en los alumnos/as acerca del término Valor, demuestra como del total de los estudiantes del grupo de $1^{\circ}$ de ESO A, sólo un $15 \%$ han sabido definir este concepto, de $1^{\circ}$ de ESO B un $38,88 \%$, de $2^{\circ}$ de ESO A un $16,66 \%$; de $2^{\circ}$ de ESO B un $26,31 \%$, de $3^{\circ}$ de ESO A un $6,25 \%$, de $3^{\circ}$ de ESO B un $57,14 \%$, de $4^{\circ}$ de ESO A un $35,29 \%$, y de $4^{\circ}$ de ESO B un $92 \%$. De forma general, todos los cursos han presentado un porcentaje de conocimiento bajo, inferior al $50 \%$, exceptuando el caso de $3^{\circ}$ de ESO B 
que ha obtenido una puntuación superior al $50 \%$ y $4^{\circ}$ de ESO B que ha obtenido una puntuación muy elevada, superior al 90\%. Significativamente estos cursos corresponden con los grupos bilingües de $3^{\circ}$ y $4^{\circ}$ de ESO. Por el contrario, en los cursos de $1^{\circ}$ y $2^{\circ}$ de ESO los alumnos/as bilingües y no bilingües están mezclados en las dos modalidades.

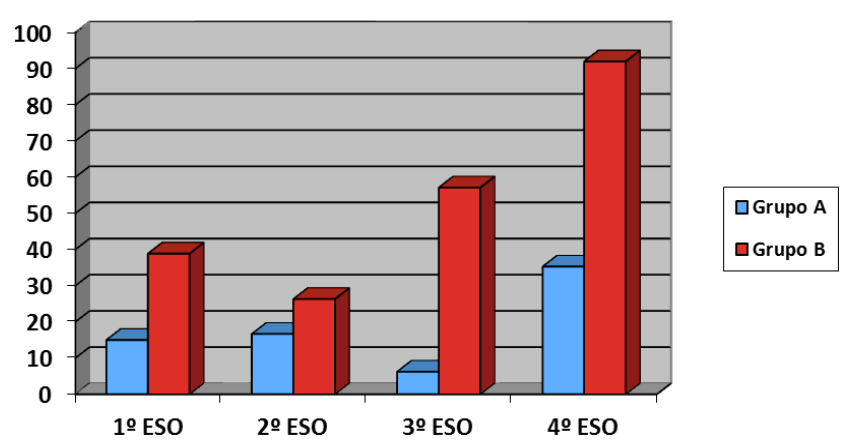

Figura 8: Porcentaje de estudiantes que ha respondido correctamente al concepto de Valor

\section{ORIENTACIONES PARA LA MEJORA DE LA EDUCACIÓN EN VALORES QUE SE TRABAJA DESDE LOS CENTROS EDUCATIVOS}

Las principales orientaciones que se proponen para la mejora de la educación en valores que se trabaja desde los centros educativos son las siguientes:

En primer lugar, se destaca la recogida adecuada de las propuestas realizadas acerca de la Educación en Valores (tutorías para trabajar los valores, desarrollo de un aula específica de convivencia, celebración de unas fechas importantes a nivel nacional o internacional y puesta en funcionamiento del alumnado mediador, entre otros ejemplos.), sobre la propia documentación del centro. De forma que, se va a requerir de una intervención sobre el Plan de Acción Tutorial y Plan de Convivencia, debido a que son los principales instrumentos que, dentro del Proyecto Educativo de Centro, integran el listado de valores que se transmiten y trabajan en el instituto a nivel de tutoría mediante el Plan de Acción Tutorial, de mejora del clima o el ambiente de convivencia a través del Plan de Convivencia, y de forma transversal por medio de las diferentes áreas y materias del currículum. Así, se van a realizar todas las modificaciones pertinentes y necesarias sobre los documentos del centro, con la finalidad de solventar y atender las diversas necesidades existentes, mejorar el clima de convivencia presente, y potenciar el conocimiento de los valores morales y su puesta en práctica entre el alumnado y el conjunto de individuos que conforman la comunidad educativa.

En segundo lugar, se destaca el trabajo colaborativo entre todos los profesionales que integran el centro, los estudiantes y las familias. Esto se debe principalmente a que la Educación en Valores es un tipo de formación que no puede dirigirse tan sólo al alumnado, por la gran diversidad existente en torno al centro (distinta edad, lugar de origen, cultura, pensamientos, madurez, creencias religiosas y políticas, etc., entre el alumnado, familias y profesorado), a la gran importancia que se le otorga a los valores en todas las áreas y materias del currículo en sí, y a la implicación que tiene la escuela en el desarrollo de la educación moral del alumnado y su potenciación y mejora como personas sociales y democráticas. Es por todo ello, por lo que se considera necesaria la implicación de toda la comunidad educativa en las distintas propuestas realizadas 
desde el centro para la mejora de la educación moral de los estudiantes (orientador/a, alumnado, tutores/as, profesorado y familias). Por medio de estas actuaciones con los agentes de la comunidad educativa se pretende crear una pieza triangular clave entre la propia figura del orientador/a, el profesorado y los padres y madres de los alumnos y alumnas, como se recoge en la figura 9, con el fin de que desarrollen un trabajo en equipo de forma conjunta, cooperativa y consensuada, y de que se impliquen en las labores educativas realizadas desde el contexto educativo con los estudiantes.

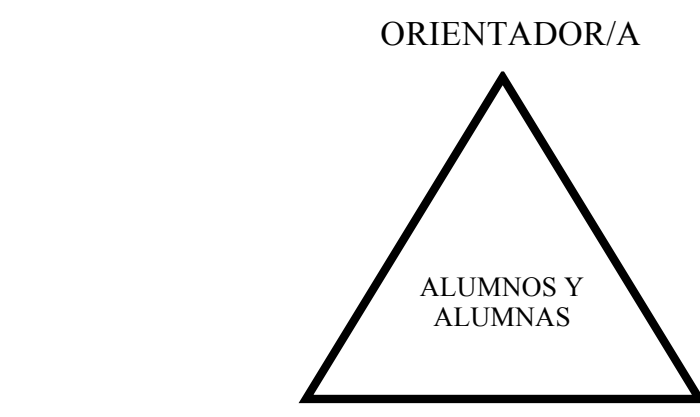

PROFESORES/AS

PADRES Y MADRES

Figura 9: Actuación triangular a desarrollar desde los centros educativos

En tercer lugar, se destaca el diseño y elaboración de una serie de actividades educativas variadas que permitan trabajar los Valores, en función de dos vías o niveles de actuación: una de prevención y otra de intervención. Ambas actuaciones deben estar recogidas dentro del Proyecto Educativo de Centro, más concretamente, en el Plan de Acción Tutorial y Plan de Convivencia.

Las tareas o actividades a nivel preventivo han de ser aquellas que traten de prevenir la existencia de una serie de problemas morales y de convivencia dentro del centro, y que traten de conseguir que todo el alumnado disponga de una base firme y estable de conocimiento moral, capaz de llegar a ser utilizado en los distintos contextos y situaciones personales. Todas estas actividades pretenden, además, que los diferentes docentes del centro y padres y madres de los estudiantes conozcan el listado de tareas que han sido propuestas desde el centro para potenciar este conocimiento en los alumnos y alumnas, y que se sensibilicen, se impliquen y participen en la transmisión de este conocimiento. Dicha propuesta puede agrupar algunas actividades como, por ejemplo, las tutorías sobre los valores, la celebración de fechas importantes a nivel nacional e internacional, y el trabajo transversal con los valores más destacados dentro de las diferentes materias escolares, entre otros.

Las actividades a nivel de intervención, por su parte, han de ser aquellas que traten de corregir y solucionar la existencia de unas conductas contrarias a la convivencia y las buenas relaciones no sólo entre los estudiantes, sino también entre éstos y los docentes, los padres y las madres, o el grupo de iguales fuera de la propia comunidad educativa. Así, debe reunir tareas relacionadas con la formación en valores dentro del aula de convivencia y el desarrollo de la mediación del alumnado, entre otros ejemplos, para resolver las disputas escolares existentes y para prevenir que éstas vayan a un nivel de mayor gravedad.

\section{DISCUSIÓN}

Las edades comprendidas entre los 12 y los 18 años son aquellas en las que los niños/as y adolescentes se encuentran en una etapa de pleno desarrollo, crecimiento y 
maduración, siendo ésta una fase idónea para ofrecerles unos conocimientos y formación específica sobre los valores, capaz de ayudarlos a conformar su propia identidad como personas, en una etapa de desarrollo en la que su perfil psicológico y emocional es muy cambiante e inestable y en la que les puede resultar muy difícil conocerse a sí mismos y a los demás, así como convivir pacífica y democráticamente dentro del grupo de iguales.

Los numerosos problemas de convivencia observados entre los estudiantes, así como las diferencias encontradas en cuanto al conocimiento de los valores en función de la edad, el nivel de maduración e incluso las modalidades bilingües y no bilingües, en el caso del alumnos y alumnas más mayores, y los diversos beneficios de la propia formación moral, me han llevado a elaborar una serie de orientaciones clave con la intención de que lleguen a todos los estudiantes, en igualdad de condiciones, y potencie el aprendizaje del conjunto de valores morales, haciendo de éste un instrumento eficaz. Dichas orientaciones pretenden despertar la motivación intrínseca de todo el alumnado, así como potenciar su aprendizaje moral, con la finalidad de garantizar la extrapolación de esta formación a otros contextos sociales externos al centro. En definitiva estas orientaciones pretenden que todos aquellos valores, que se suponen que se van adquiriendo principalmente en la familia (el respeto, igualdad, libertad, etc.), puedan ser afianzados en la escuela y queden arraigados en todo el alumnado, de forma perenne y duradera.

\section{REFERENCIAS}

Aebli, H. (2002). 12 Formas básicas de enseñar. Una didáctica basada en la filosofía. Madrid: Narcea.

Alonso, J. (1999). La motivación y aprendizaje en la enseñanza secundaria. En Coll, C. (coord.), Psicología de la instrucción: la enseñanza y el aprendizaje en la educación secundaria. Barcelona: ICE-Horsori.

Alonso, J. (2005). Motivaciones, expectativas y valores-intereses relacionados con el aprendizaje: el cuestionario MEVA. Psicothema, 17(3), 404-411.

Álvarez, C., y Gutiérrez, R. (2013). Educar en valores a través de un club de lectura escolar: un estudio de casos. Revista Complutense de Educación, 24(2), 303319.

Álvarez, M., y Bisquerra, R. (2012). Orientación educativa. Modelos, áreas, estrategias y recursos. Madrid: Wolters Kluwer.

Barreto Nieto, A. (2012). Educar en valores inteligentes. Para niños, jóvenes y adultos. Madrid: CCS.

Bouché, H. (2005). Educar para la motivación. En Cultivar los sentimientos: Propuestas desde la filosofía de la educación (pp. 195-222). Madrid: Dykinson.

Casado, A., y Sánchez, J. (1999). Valores y educación: una investigación sobre perfiles valorativos. Tendencias pedagógicas, 4, 141-155.

Casares, P. (1995). Test de Valores: Un instrumento para la evaluación. Revista Española de Pedagogía, 202, 513-537. 
Casares, P. (2008). Valores, afectividad y desarrollo de la persona: aspectos convergentes e implicaciones educativas. En Touriñán, J.M. (Dir.), Educación en valores, educación intercultural y formación para la convivencia pacífica (pp.76-87). La Coruña: Gesbiblo.

Casares, P., Carmona, G., y Martínez, F. (2010). Valores profesionales en la formación universitaria. Revista electrónica de investigación educativa, 12, 1-15.

Cid, S. (2008). El uso de estrategias de aprendizaje y su correlación con la motivación de logro en los estudiantes. Revista Iberoamericana sobre Calidad, Eficacia, y Cambio en Educación (REICE), 6(3), 100-120.

Eccles, J.S., y Wigfield, A. (2002). Motivational beliefs, values and goals. Annual Review of Psychology, 53, 109-132.

Escámez, J. (1998). Educar en la autonomía moral. Valencia: Generalitat.

Escámez, J. (2003). Pensar y hacer hoy educación moral. Teoría de la educación. Revista interuniversitaria, 15, 21-31.

Escámez, J., García, R., Pérez, C., y Llopis, A. (2007). El aprendizaje de valores y actitudes. Teoría y práctica. Madrid: Octaedro.

Fiorini, M., \& García-Ramírez, JM. (2013). Cap. 5: Técnicas de grupo y creatividad aplicadas en el ámbito universitario, en Villena, MD., Muñoz, A. Recursos para tutoría en el aula universitaria. Granada: Editorial Universidad de Granada.

Gálvez, A.M. (2006). Motivación hacia el estudio y la cultura escolar: Estado de la cuestión. Pensamiento Psicológico, 2(6), 87-101.

García-Ramírez, J.M. (2012). La comunicación, clave de excelencia visible en la Educación Superior. Journal for Educators, Teachers and Trainers , 3, 25-36.

Guaman, M. (2013). Valores y estilo de vida en niños, niñas y adolescentes de octavo y noveno año de educación general básica, estudio realizado en el Instituto Tecnológico Superior "Primero de Mayo" de la ciudad de Yantzaza en el año lectivo 2012-2013. (Tesis doctoral). Universidad Técnica Particular de Loja, Centro Universitario Zamora.

Hidi, S. y Harackiewicz, J.M. (2000). Motivating the academically unmotivated: a critical issue for the 21 st century. Review of Educational Research, 70(2), 151-179.

Lobato, A., y Morilla, M. (2007). Ideas y recursos para el desarrollo de la educación en valores. Sevilla: Fundación ECOEM.

López, F. (2005). Metodología Participativa En La Enseñanza Universitaria. Madrid: Narcea.

Manassero, M.A. (1998). Validación de una escala de motivación de logro. Psicothema, 10(2), 333-351.

Marina, A. (1998). El laberinto sentimental. Barcelona: Anagrama. 
Martín, X., y Puig, J. M. (2007). Las siete competencias básicas para educar en valores. Barcelona: Graó.

Martínez, M., Puig, J.M., y Trilla, J. (2003). Escuela, profesorado y educación moral. Teoría de la educación, 15, 57-94.

Mora, G., Sarmiento, E., y Ossa, J. (1995). Valores humanos y actitudes positivas. Colombia: McGraw Hill.

Pérez, E. (2001). Enseñanza y cultura escolar. Revista de Teoría Didáctica de las Ciencias Sociales, 6, 104-114.

Rodriguez, R. M. (2012). Educación en valores en el ámbito universitario. Propuestas y experiencias. Madrid: Narcea.

Shaaban, K. (2006). An initial study of the effects of cooperative learning on reading comprehension, vocabulary acquisition, and motivation to read. Reading Psychology, 27(5), 377-403.

Touriñán, J. M. (2008a). La educación en valores como uso y construcción de experiencia axiológica. En Touriñán, J.M. Educación en valores, educación intercultural y formación para la convivencia pacífica. La Coruña: Gesbiblo.

Touriñán, J. M. (2008b). Posibilidad y necesidad en la educación en valores. En Touriñán, J. M. Educación en valores, educación intercultural y formación para la convivencia pacífica (pp. 12-31). La Coruña: Gesbiblo.

Tust, M., y Martínez, L. (2006). Educación en valores y ciudadanía. Propuestas y técnicas didácticas para la formación integral. Madrid: Catarata. 